\title{
On the Optimal Social Contract: Agency Costs of Self-Government
}

\author{
Sang-Hyun Kim*
}

November 20, 2013

\begin{abstract}
In a typical study of political economy, citizens are regarded as principals, and government as agent. This is a modern way of thinking in the sense that classical theorists of democracy such as Jean-Jacques Rousseau and James Madison were more interested in the dual nature of people; they are principals (citizens sharing the sovereign power) and, at the same time, agents (subjects under the laws). Government, in their framework, is an intermediate body which helps people solve their self-control problem. Equipped with tools of modern economics, this paper explores the classical problem to see how economic development and political institutionalization relate to the structure of government and the quality of public sector. In particular, I consider repeated games with a large population and incomplete information, in which players decide whether to sacrifice private consumption to provide public goods. Because both people and the executive of public projects are subject to moral hazard, the people spend resources to monitor the executive and the people themselves. The optimal self-enforcing contract, which can be interpreted as an efficiency upper bound of political systems, is characterized. The analysis of the contract shows that as a country gets more economically developed and politically institutionalized, the agency problem on the people's side becomes negligible, and the citizens' demand for accountable government becomes stronger, in which case the standard principal-agent framework is good enough to describe the political reality.

Keywords: Social contract, Democracy, Principal-agent problem, Self-enforcing political regime, Economic development

${ }^{*}$ School of Economics, University of East Anglia, Norwich, UK; E-mail: kimsan46@gmail.com; I thank Jay Pil Choi, Christian Ahlin, John D. Wilson and Andrei Shevchenko for warm guidance and valuable comments.
\end{abstract}




\section{Introduction}

It has been well noted in the literature of democracy and development that the political systems of poor countries differ markedly from those of rich ones. Evidence shows that low level of economic development is strongly correlated with low levels of civil liberty and public good provision, poor government accountability, and more regulations on economic activities. ${ }^{1}$ Economists and political scientists have rightly identified the causal mechanisms from one side, the quality of public sector, to the other, economic performance, while the possibility of reverse causality has rarely been explored. It is partialy because in modern literature of political economy, individuals are typically regarded as the principals, and government as the agent. ${ }^{2}$ In standard principal-agent models, economic status of the principals (i.e. citizens' wealth in political economy models) does not affect the outcome of the model, because regardless of whether they are poor or rich, the principals want to extract the maximum surplus from their agent. ${ }^{3}$ This contrasts sharply with the fact that the agent's pre-contract economic status, which affects the marginal utility of monetary compensation, the reservation value, etc., is one of the key determinants of the outcome. This paper, investigating models in which citizens play the role of agents as well as that of principals, shows that poor economic performance of a country might prevent the citizens from establishing a more efficient public sector.

The idea that citizens are agents as much as they are principals in politics is by no means new. It is firstly formalized by classical theorists of democracy such as Jean-Jacques Rousseau and James Madison. For instance, Rousseau identified individuals differently depending on the role that they play.

"Those who are associated in [the republic] take collectively the name of people, and severally are called citizens, as sharing in the sovereign power, and subjects, as being under the laws of the State." Jean-Jacques Rousseau, On the Social Contract, Book I, Chapter 6.

By this distinction, Rousseau made it clear that building a political assocation (i.e. a republic) is at the most fundamental level to solve the self-control problem; in other words,

\footnotetext{
${ }^{1}$ See for example Keefer (2007), La Porta et al. (1999) and references therein.

${ }^{2}$ For studies applying principal-agent framework to the problem of government accountability, see Laffont (2000) and Besley (2006) among others.

${ }^{3}$ Of course, this is not true if the principal is financially constrained. But typically, the political principals are not financially constrained, because the agent is incentivised not by direct monetary transfers but by continuation of a privileged position.
} 
to avoid the "war of all against all" (Thomas Hobbes). So, we can say, using the language of modern economics, that in Rousseau's social contract, individuals appear twice in completely different positions, once in the position of the ultimate principals (citizens) and in that of the ultimate agents (subjects).

"What then is government? An intermediate body set up between the subjects and the Sovereign, to secure their mutual correspondence, charged with the execution of the laws and the maintenance of liberty, both civil and political." Book III, Chapter 1.

The relationship of citizens and government here is more complicated than what a simple principal-agent model assumes. It resembles a "hierarchy", a chain of principal-agent relationships, but differs from usual hierarchies in that the top-ranked principal and the bottom of the chain are the same people. This circular hierarchy was also identified by James Madison who wrote:

"If men were angels, no government would be necessary. If angels were to govern men, neither external nor internal controls on government would be necessary. In framing a government which is to be administered by men over men, the great difficulty lies in this." Alexander Hamilton, John Jay and James Madison, The Federalist Papers, No. 51.

Because men are not angels, they hire an agent to be a principal. But this principal is also subject to agency problem which would reduce the efficiency of the people's self-control. In short, the social contract creates multiple principal-agent relationships which potentially exacerbate each other.

Starting with a simple repeated game with a continuum of players who decide whether to sacrifice their private consumption to provide public goods, I explore properties of Rousseauian social contract. The social contract differs from usual contracts in that it lays the foundation of the law and order. Because it cannot rely on pre-existing laws, the social contract must be self-enforcing, i.e. the players must find it optimal to voluntarily give their natural liberty (or private goods) up so as to enjoy the civil liberty (or public goods). This means that the social contract is not perfectly enforceable, which is a source of the agency problem. One of the main results of this paper is that this requirement of self-enforcement makes any changes in the agency costs be endogenously amplified. To see how it works, suppose that by an 
exogenous reason, the quality of the public projects is improved. This change increases the value of being a citizen, i.e. increases the opportunity cost of violating the laws of the society. Hence, now a smaller amount of resources is required to incentivise the citizens; in other words, the state needs less police officers and less bureaucrats, which means the overall efficiency of public good production is further improved. This, of course again, increases the value of the social contract, and allows the republic to further reduce the cost of watching over the private sector.

This positive feedback mechanism can also amplify the changes which negatively affect the value of the social contract. For instance, suppose by a natural disaster, national broadcasting systems are destroyed, which supposedly would make the government less accountable. An increase of the agency cost on the government side reduces the value of the social contract, which in turn increases the amount of resources required to incentivise the citizens. That is, the agency costs on the citizens' side also increases, which further triggers reductions in the value of the social contract.

In Section 4, the optimal social contract, which allocates resources to maximize citizens' expected utility, is characterized in a more flexible setup. This contract can be interpreted either as an efficiency upper bound of political systems or as the social demand for accountable government. The analysis shows that the resource spent in disciplining the executive of public projects must increase as the citizens' wealth is enhanced. When the citizens' economic status is improved, the marginal utility of private consumption is reduced, which means that the marginal utility of public good comsumption in relative term (i.e. the marginal rate of substitution) increases. As the value of being a citizen becomes greater, now the republic can divert resources from monitoring citizens to actually producing public goods. It means that the effective size of the public investment grows larger, and consequently, the citizens find it optimal to put more resources in monitoring the executive, i.e. to demand for more checks-and-balances, more institutionalization and so on. Thus, the analysis suggests that the structure and quality of the public sector of a country would be affected by the wealth level of its citizens.

By endogenizing the wealth level of individuals, I also illustrate a "dynamic" feedback mechanism. Section 5 provides an analysis of a simple growth model which combines the modern view (namely, the quality of public sector affects economic performance) and the classical view (economic, social and political fundamentals affect the structure and quality of public sector) together. I show that if the quality of public sector affects economic performance of the country, there might exist a poverty trap in which a country stays poor because it cannot 
overcome its citizens' agency problem. In the poverty trap, the citizens are given a low level of capital stock at the begining of a period, which limits their production capacity. As a result, their income level ends up being low. As shown in the static analysis, the agency costs are particularly high when the level of income is low. Thus, the government's ability to provide public goods such as social infrastructure, public education, health care etc., would be seriously limited, which is detrimental to the economy's expected productivity in the future. Since the expected return from private investment is low, the citizens will invest little, which results in a low level of capital stock in the next period. Thus again, low incomes will be given to the citizens. If the punishment capacity of government is in the intermediate range, there exist multiple steady-state equilibria in one of which a country is able to establish an efficient political system because its initial endownment of productive resources were abundant, whereas in the other the country is trapped in poverty.

The models presented in this paper are not designed to immediately generate theoretical predictions. Instead, they help identify obstacles lying on the way to build a better government, and to that extent, the models provide insights in relation with the empirical patterns documented in the literature. For example, La Porta et al. (1999) find that richer countries enjoy more efficient public sector, better public good provision, larger government, and higher level of political freedom. According to the theoretical result presented in Section 4, efficient public sector and high level of civil liberty are available only when the agency problem on citizens' side is efficiently dealt with, a necessary condition of which might be that the citizens' overall wealth level is high enough. Keefer (2007, p.887) summarizes his findings as "poorer countries make significantly different choices along [many] policy dimensions than richer countries; these are not easily explained by regime type. However, consistent with the ambiguous effects of democracy on growth, the policy choices of poor democracies differ little from those of poor non-democracies!" In Section 6, I discuss the possibility that non-democracies might be able to perform better than democracies by punishing misbehaving citizens more severely. Przeworski et al. (2000) provide a comprehensive assessment on the dynamic relationship between political regime and economic development. They do not find any evidence that higher economic wealth causes transition to democracy, but do find that economic prosperity stabilizes the political regime, which is consistent with the analysis of regime stability presented in Section 3 .

A few previous studies have explicitly considered the agency problem on citizens' side in dynamic political economy models. In a model where a self-serving politician provides public goods and citizens can partially evade taxes, Acemoglu (2005) show that both too weak and 
too strong states might impede economic development. His analysis focuses on the effect of the "power" of government on economic performance, whereas I focus on how economic development and other underlying factors affect the structure and effeciency of governments. Acemoglu et al. (2010) study dynamic Mirrlees taxation under the assumption that political elites have self-serving motivation. Their model is a circular hierarchy in the sense that the citizens discipline politicians by the threat of replacement, while the government implements non-linear taxation scheme to reveal citizens' hidden types. The source of the agency problem on citizens' side in their paper is the asymmetric information, where as in the present paper, the source is the imperfect enforceability of social contracts. The two studies mentioned here do not endogenize the structure of government, whereas Acemoglu et al. (2011) do examine how a government with an inefficient structure can emerge and persist even when more efficient structures are feasible. They assume the government's ability to collect taxes depends upon the size of the bureaucracy which is decided by political elites. And, they show that political elites might want to have more than enough bureaucrats to capture democratic politics, so eventually to hinder redistribution of wealth. To my best knowledge, none of previous works explored the effect of citizens' wealth on the structure and quality of government in principalagent framework as this paper does.

Lagunoff (2001) considers citizens' self-regulation problem in a very different setup. In his model, citizens have heterogenous preference over an issue, and democratically (i.e. along the preference of the median voter) establish the law which every citizen must obey. Because the law enforcement is subject to errors, the median voter has an incentive to establish more tolerant legal system even when she has no intrinsic preference for "civil liberty." Unlike the studies cited above, Lagunoff does not explicitly consider the incentives of politicians or bureaucrats. Instead, focusing on the median voter's incentive, his work provides an explanation why tolerance, which may result in inefficiencies in law enforcement, would be chosen over most extreme punishment in equilibrium.

This study is also closely related to the repeated game literature. ${ }^{4}$ The game that I consider here is a sort of repeated Prisoner's Dilemma with a superstructure which is called the government and infinitely many players. The maximum cooperation in a typical repeated PD corresponds to the optimal social contract in this paper. One of the most notable features of the cooperative equilibria in both games is that they are self-enforcing, i.e. the "contract" does not require a third party who enforces it. Self-enforcement is a natural requirement for

\footnotetext{
${ }^{4}$ Mailath and Samuelson (2006) provide a comprehensive summary of the literature.
} 
a social contract which is the foundation of law and order of a society.

In that sense, the studies of self-enforcing political regimes are direct precedents of the current paper. Przeworski (2005) and Fearon (2011) investigate when and why fair and regular elections are preferred by political elites, and how a democratic regime can be sustained as an equilibrium. Key idea is that since political elites cannot credibly make a commitment to giving up their power, a democratic regime can be sustained only when giving up power is more beneficial for themselves. ${ }^{5}$ Whereas they focus on incentives of political elites, the main focus of this paper is on the citizens'.

The rest of the paper is organized as follows. In the next section, I lay down the baisc setup and the equilibrium concept. Section 3 demonstrates how a self-enforcing contract works in the simplest setup. In Section 4, I characterize the optimal social contract, and analyze the structure and quality of it. A growth model is presented in Section 5. I briefly discuss the roles of political institutions in Section 6. Finally, I conclude in Section 7, discussing a sociological hypothesis on why the self-control problem of people has been largely ignored in the literature.

\section{Model}

The basic model is a repeated public-good game with a continuum of players. In each period, the players decide whether to give up some portion of private consumption for production of public goods. The public goods here may include, but not be limited to, law and order, national security, social infrastructures such as bridges and roads, public sanitation, public education and so on. Correspondingly, providing public goods, or paying tax, in this model can be interpreted broadly as abandoning private economic gains for public welfare. To incentivise themselves and the executive of the public project, people establish public agencies which monitor and punish those who breach the contract.

\subsection{Environment}

Consider a society with a continuum of individuals $i \in[0,1]$ and infinately many identical politicians both of whom live in $t=1,2, \ldots \infty$. In each period, an individual is endowed with

\footnotetext{
${ }^{5}$ A similar idea is examined by Acemoglu (2003).
} 
$\underline{x}_{i t}$ unit of non-taxable income and one or zero unit of taxable income:

$$
y_{i t}=\left\{\begin{array}{l}
1 \quad \text { with prob. } y_{t} \\
0 \quad \text { with prob. } 1-y_{t}
\end{array}\right.
$$

where the aggregate level of taxable income $y_{t}=\int y_{i t} d i$ is independently drawn from distribution $F$. Let $\mu$ be the mean of $y_{t}$. Then, the unconditional mean of $y_{i t}$ is also $\mu$. Whereas the distribution of $y_{t}$ is commonly known, each realization $y_{i t}$ is observed only by person $i$. So, $y_{t}$ is not observable to anybody. This assumption prevents a person's tax evasion from being immediately observed and punished. A person endowed with $y_{i t}=1$ decides whether to consume it privately or submit it for public good production. Denote $x_{i t} \in\{0,1\}$ the consumption decision: $x_{i t}=0$ if individual $i$ pays the tax, and 1 if consumes it privately. Thus, the total private consumption is either $\underline{x}_{i t}$ or $\underline{x}_{i t}+1$. Consumption decision is observable to other players if and only if the individual pays the tax. Saving is not allowed in the basic model.

To introduce moral hazard problem of the executive of the public project, who is randomly chosen from the pool of politicians, I assume that the public good production succeeds in a stochastic manner. Precisely, from $g$ unit of the input (i.e. the collected private good), $\gamma g$ unit of public good is produced with probability $p$, and with the complementary probability, the project fails:

$$
G_{t}=G\left(g_{t}\right)=\left\{\begin{array}{cl}
\gamma g_{t} & \text { with prob. } p \\
0 & \text { with prob. } 1-p
\end{array}\right.
$$

Once the public project succeeds, everybody in the polity equally enjoy the benefit. Assume the tax revenue $z_{t}=y_{t}-x_{t}=\int\left(y_{i t}-x_{i t}\right) d i$ is observable, but the actual amount of input of the public project, denoted by $g_{t} \leq z_{t}$, is not observable to the citizens. So, when the outcome of the project $G_{t}$ is zero, the citizens cannot tell whether the project failed due to bad luck, or the executive officer diverted the entire public fund for private use. They come to know the actual amount of resources invested only when $G_{t}$ is positive. I will denote the legitimate rent given to the executive officer by $w_{t}=w\left(z_{t}\right)$.

After the outcome of the project is publicly observed, the citizens jointly decide whether to replace the executive officer, which costs them as much as $R$. $R$ would be high, if the replacement involves a risk of military coup and following turmoils. In costrast, $R$ would be low if the state is politically well-institutionalized; if fair, free and regular elections are held, if citizens' interests are not extremely polarized, if overall performance of the executive is clearly observable and so on. Throughout the paper, I will take $R$ as exogenously given. More 
discussions with regard to political institutionalization will be provided in Section 6 .

So, the instantaneous utility given to a citizen in each period is

$$
u\left(\underline{x}_{i t}+x_{i t}\right)+G_{t}+R_{t}-E\left(s_{i t}\right)
$$

where

$$
R_{t}=\left\{\begin{array}{cc}
R & \text { if replace the executive } \\
0 & \text { if keep the executive }
\end{array}\right.
$$

$E\left(s_{i t}\right)$ is the expected punitive sanction given to $i$ in period $t$, and $u(\cdot)$ is an increasing and strictly concave function. In Section 3 and 4, I assume that citizens are ex-ante homogenous and endowed with fixed non-taxable income, i.e. $\underline{x}_{i t}=\underline{x}$ for all $i$ and $t$. This assumption is partially relaxed in later sections.

Although terminologies of public finance (e.g. taxable income, tax revenue, etc.) were used to describe the model, the aim of this paper is not in analyzing a taxation problem in the real world. Instead, paying tax in the model should be interpreted more broadly as abandoning private economic gains for public welfare. For instance, suppose $y_{i t}=1$ if an opportunity to steal another's belongings is given to individual $i$, and $y_{i t}=0$, otherwise. Then, the decision of $x_{i t}$ is whether to respect the other's property right, and the produced public good is secure property rights for everybody. Collectively, the benefit of it must be greater than the simple benefit of not losing properties, because individuals do not have to exert effort to keep their belongings safe in already safe enviornments. Alternatively, $y_{i t}$ could represent an opportunity for financial fraud, counterfeit, polluting rivers or even traffic violation.

\subsection{Monitoring agencies}

Two public agencies are established to monitor two sides of the society. On one side, as argued by Thomas Hobbes, it is too costly for a large number of individuals to monitor and punish each other in a less institutionalized manner. So, they delegate the tasks to one of the public agencies. On the other side, the executive officer of the public project can divert the collected resources for personal use if she is willing to take the risk of being replaced, while the incomplete information about $g_{t}$ makes such illegitimate appropriation hard to detect. So, the other agency is assigned to audits the executive.

In the following, these two agencies will be referred to as External Monitoring Agency (EMA) and Internal Monitoring Agency (IMA). The role of EMA is, like a tax agency such as IRS in the U.S., to monitor citizens whether to pay taxes when they have to. This government agency can randomly monitor $\phi\left(n_{E}\right)$ fraction of citizens where $n_{E}$ is the number of civil servants 
working in EMA. On the other hand, IMA checks the working of the executive. More precisely, I assume that if the office holder diverts the public resource, such misbehavior is detected with probability $\psi\left(n_{I}\right)$, and the fund is impounded where $n_{I}$ is the number of employees working in IMA. Even if she gets caught, zero public good is provided in that period, since the opportunity to produce the public good is lost.

In order to focus on the citizens' self-control problem, I simply assume that $\phi(\cdot)$ and $\psi(\cdot)$ are well-behaving, non-decreasing functions, without explicitly modeling the bureaucratic organizations. ${ }^{6}$ In particular, the monitoring capacity of EMA $\phi(\cdot)$ is twice-differentiable, increasing and strictly concave. Let us also assume $\phi(0)=0$, and $\lim _{n \rightarrow 0} \phi^{\prime}(n)=\infty$. For $\psi(\cdot)$, I consider two different forms of functions. In Section 3, I employ the following step function:

$$
\psi\left(n_{I}\right)= \begin{cases}1 & \text { if } n_{I} \geq c_{I} \\ 0 & \text { otherwise }\end{cases}
$$

where $c_{I}$ is an exogenously given threshold. In words, if a certain amount of resource is expended in monitoring the executive, the information asymmetry is completely removed, and the politician is perfectly disciplined. This functional form allows me to clearly demonstrate how the agency problem on the government side exacerbates its counterpart on the citizens' side. In Section 4, I assume that $\psi(\cdot)$ is a twice-differentiable, increasing and strictly concave function to see how the optimal level of $n_{I}$ responds to changes in the fundamentals.

The above description should not be taken literally. Instead, $n_{E}$ and $n_{I}$ should be regarded as the total resources spent in dealing with the agency problems or as measures of the agency costs. Denote $n_{P} \equiv 1-n_{I}-n_{E}$ the number of citizens working in the private sector. Let us assume that the agency problems are detrimental to the public welfare; specifically, assume that only the citizens who work in the private sector have the opportunity to get the additional income, i.e. $y_{i t}$ is always 0 if $i$ works in the public sector, while the baseline income $\underline{x}$ is preserved. Under this assumption, the input $g_{t}$ must be smaller than or equal to $n_{P}$, and therefore, the effective size of the public project shrinks as the agency costs grow larger.

\subsection{Timing of the events}

In each period, an individual as a subject under the laws decides whether to give up the taxable income when it is given, and as a citizen whether to replace the executive officer. The office holder maximizes her discounted utility by choosing how much to divert the public fund. The events take place in the following order.

\footnotetext{
${ }^{6} \mathrm{~A}$ similar approach is taken by Acemoglu et al. (2011).
} 
1. The citizens jointly decide the size and structure of their government $\left(n_{I}, n_{E}\right)$ and the wage schedule for the politician $w(\cdot)$ to maximize their expected utility.

2. The public sector is filled in. The individuals hired in the public sector must give up the opportunity obtain the taxable income $y_{i t}$.

3. EMA secretly and randomly chooses $\phi\left(n_{E}\right)$ fraction of citizens who will be investigated.

4. $y_{i t}$ is realized and observed only by individual $i$ who then makes a binary decision $x_{i t} \in$ $\{0,1\}$ in case that $y_{i t}=1$. Both $x_{i t}$ and $y_{i t}$ are private information unless the individual is investigated by EMA in period $t$.

5. The tax revenue $z_{t}$ is collected and publicly observed. The politician secretly decide how much of the public fund to divert in addition to the legally given wage $w\left(z_{t}\right)$.

6. The outcome of the public project $G_{t}$ is realized.

7. Observing $G_{t}$, the citizens collectively decide whether to replace the executive officer. In case of replacement, the office is filled by another randomly chosen politician.

8. IMA and EMA inspect their monitoring objects, and punishments are imposed if any misbehavior is detected. If there is no replacement, IMA investigates no one.

9. All agents consume what is given to them.

Before proceeding further, a few remarks may clarify the setup. First, the assumption that citizens decide the size and structure of their government captures the fact that institutional features of governments are shaped largely by the consititution. In reality, the composition of governments would be distorted by many factors. ${ }^{7}$ Addressing these issues thoroughly, however, is beyond the scope of this paper. An alternative assumption which could generate the same outcome, provided that the underlying parameters are not changing, is that $\left(n_{I}, n_{E}\right)$ are set up by benevolent founders of the republic in period $t=0$. Also note that for the model presented in Section 4, we could have adopted an alternative assumption, namely that $\left(n_{I}, n_{E}\right)$ and $w(\cdot)$ are announced by the politician in the office at the beginning of each period, and the citizens replace the politician if $\left(n_{I}, n_{E}\right)$ and $w(\cdot)$ are not set up to maximize their utility.

In any equilibrium where citizens in the private sector pay their tax (i.e. $x_{i t}=0$ for all $i$ and $t$ ), the individuals are indifferent between working in the private and in the public sector.

\footnotetext{
${ }^{7}$ Acemoglu et al. (2011) provides an example of such distortions. Or the government could be designed to pursue a different goal such as maximizing the welfare of political elites.
} 
Thus, conditional on that the public investment takes place, the tuple $\left(n_{I}, n_{E}\right)$ is completely determined by the decision made at the beginning of each period.

Note also that the assumption that EMA inspects randomly chosen citizes would not be a big loss of generality if the citizes are ex-ante homogenous. EMA can use a different inspection strategy by making an articificial distinction among the citizens, but analyzing such strategies is beyond the scope of this paper. One may argue that EMA can work more efficiently by focusing on those who did not pay taxes, instead of randomly monitoring every citizen. However, even if EMA investigates those who did not pay the tax, the monitoring capacity would still be an increasing function of $n_{E}$, and therefore, the qualitative results of this paper remain valid. Alternatively, the random inspection can be justified by assuming that due to administrative lags, EMA does not know who did not pay taxes when they investigate the private sector.

Recall that if a decision is made by voting in a society with a large population, any outcome can emerge as equilibrium. Here I focus on equilibria in which the citizens jointly make the decision whether to replace the current office holder. I assume that punishing a citizen is costless for the government.

\subsection{Equilibrium}

For the most part of the paper, I focus on self-enforcing social contracts in which the participants of the contract can freely opt out of the contract. It implies that the continuation utility for punished individuals cannot be lower than the expected utility in anarchy. Of course, in reality, a criminal cannot freely avoid punishment by giving up his citizenship. But, international organizations such as United Nations and Human Rights Watch put pressure on the governments on earth to recognize "human rights" of criminals and prisoners. And, the expected utility of anarchy in the model can be read as the life-time utility when only minimal "human rights" are promised. So, the self-enforcing contracts can be understood as the republics constrained to recognize the human rights, and the optimal contract is the efficiency upper bound with the constraint. ${ }^{89}$ In Section 5 and 6 , I consider situations where the limit

\footnotetext{
${ }^{8}$ In deriving the results of this paper, the requirement of self-enforcement is not crucial. As long as the exogenously given limit of punishment is finite (i.e. the contract is imperfectly enforceable), the properties of social contracts would remain qualitatively the same.

${ }^{9}$ One may ask why the government cannot make the misbehaving citizens infinitely miserable. One reason for not employing the most severe punishment scheme would be human imperfection in making judgement. That is, when law enforcement is subject to errors, citizens would prefer to tolerate misbehavior to some degree
} 
of punishment is not bound by the anarchy benchmark.

Not surprisingly, there exist infinitely many Subgame Perfect Equilibria in the models. For instance, in addition to "working" social contracts, there always exists the anarchy equilibrium where everybody pursues their private gains againt the public welfare. Thus, instead of trying to characterize as many SPE as possible, I focus on a Markov Perfect Equilibrium in which the expected utility of citizens is maximized. This optimal social contract can be interpreted in two ways. First, as mentioned above, it is an upper bound for efficient public good provision. Thus, the analysis provides a suggestive answer to the question why some countries with poor public sector could not do better. Second, it can also be interpreted as the "social demand" for a higher-quality public sector. Just as Marshallian demand for a private good is derived from consumers' maximization problem, the social demand for a better political system would be derived as the solution of the social contract problem. Obviously, the latter interpretation would generate stronger empirical implications.

In the optimal social contract, citizen $i$ maixmizes her discounted utility

$$
\max _{x_{i t}} \sum_{s=0}^{\infty} E_{t} \beta^{s}\left[u\left(\underline{x}+x_{i, t+s}\right)+G_{t+s}-R_{t+s}-s_{i, t+s}\right]
$$

subject to

$$
x_{i, t+s} \leq y_{i, t+s} \text { for all } t \text { and } s .
$$

For simpler exposition, I rescale the instantaneous utility for each period by subtracting $u(\underline{x})$ and then dividing it by $u(\underline{x}+1)-u(\underline{x})$ :

$$
\begin{aligned}
& \sum_{s=0}^{\infty} E_{t} \beta^{s}\left[\frac{u\left(\underline{x}+x_{i, t+s}\right)-u(\underline{x})}{u(\underline{x}+1)-u(\underline{x})}+\frac{G_{t+s}-R_{t+s}-s_{i, t+s}}{u(\underline{x}+1)-u(\underline{x})}\right] \\
= & \sum_{s=0}^{\infty} E_{t} \beta^{s}\left[x_{i, t+s}+\widehat{G}_{t+s}-\widehat{R}_{t+s}-\widehat{s}_{i, t+s}\right]
\end{aligned}
$$

where

$$
\widehat{G}_{t} \equiv \frac{G_{t}}{u(\underline{x}+1)-u(\underline{x})}
$$

and $\widehat{R}_{t}$ and $\widehat{s}_{i t}$ are similarly defined. Let us also define

$$
\begin{aligned}
\widehat{\gamma}(\underline{x}) & =\frac{\gamma}{u(\underline{x}+1)-u(\underline{x})}, \\
\widehat{R}(\underline{x}) & =\frac{R}{u(\underline{x}+1)-u(\underline{x})}
\end{aligned}
$$

in order to avoid punishing the innocent. See Lagunoff (2001) for a discussion of related issues. 
Note that $\widehat{\gamma}(\underline{x})$ is the "marginal rate of substitution" between the private and the public goods. Given the size of the public project (or the tax burden given by $y_{i t}=1$ ), the MRS is increasing as the baseline income $\underline{x}$ grows larger. Throughout the paper, I assume that providing the public good is socially optimal, i.e. $\widehat{\gamma}(\underline{x}) \mu p>1$. Similarly, the "effective" cost of replacement $\widehat{R}(\underline{x})$ also becomes larger as $\underline{x}$ increases. ${ }^{10}$

On the other hand, the politician in the office is assumed to maximize

$$
\max _{T_{t}} \sum_{s=0}^{\infty} E_{t} \beta^{s} O_{t+s}\left[w\left(z_{t+s}\right)+(1-\psi) T_{t+s}\right]
$$

subject to $T_{t} \leq z_{t}-w\left(z_{t}\right)$ for all $t$, where

$$
O_{t}=\left\{\begin{array}{l}
1 \text { if holding the office at } t \\
0 \quad \text { otherwise }
\end{array}\right.
$$

$w\left(z_{t}\right)=z_{t}-g\left(z_{t}\right)$ is the wage for the executive as a function of the tax revenue $z_{t}$, and the choice variable $T_{t}$ is the diverted public fund ( $T$ for theft). Because the misbehavior is detected with probability $\psi\left(n_{I}\right)$, the office holder can enjoy the fruit of it with probability $1-\psi$.

The "working" optimal social contract is the list of the government compostition $\left(n_{I}, n_{E}\right)$, the wage schedule $w:[0,1] \rightarrow[0,1]$, the payment schedule $\left\{\mathbf{x}_{i}\right\}_{i \in[0,1]}$, the replacement strategy $\Lambda:[0,1] \times[0,1] \rightarrow\{0,1\}$ and illegitimate appropriation by the politician(s) $T::[0,1] \rightarrow[0,1]$ such that

- $\left(n_{I}, n_{E}\right)$ and $w(\cdot)$ are set up to maximize (2) subject to the incentive compatibility constraints.

- Given the state variables $\left(n_{I}, n_{E}, y_{i t}\right)$ and the wage schedule $w(\cdot)$, individual $i$ maximizes (2) by choosing $x_{i t}$

- Given the state variables $\left(O_{t}, z_{t}\right)$ and the scheduled wage $w\left(z_{t}\right)$, the politician chooses $T_{t}$ to maximize (3).

- Observing $\left(z_{t}, G_{t}\right)$, the citizens decide to replace the politician if she fails to produce the expected amount of the public good, i.e. $\Lambda\left(G_{t}, \gamma g\left(z_{t}\right)\right)=1$ if $G_{t}<\gamma g\left(z_{t}\right)$.

- The individuals working in the private sector find it optimal to pay the tax $\left(x_{i t}=0\right.$ for all $y_{i t}$ ). The government jobs are filled in as planned.

\footnotetext{
${ }^{10}$ Przeworski (2005) formally argues that the higher cost of social conflicts in richer society can be a source of the observed relationship between the economic development and democracy.
} 
The last requirement is the condition for "working" social contracts. To focus on such contracts, I assume that both $\widehat{\gamma}(\underline{x}) \mu p$ and $\beta p$ are large enough.

\section{People as Agents}

In this section, I take a close look at the incentive compatibility condition for the people, and demonstrate the following. First, as the government becomes less accountable, the agency problem on the citizens' side becomes more severe. Second, as the baseline income $\underline{x}$ grows, the agency cost becomes smaller. And, I also show that there exists a positive feedback mechanism with respect to the monitoring $\operatorname{cost} n_{E}$. Lastly, the contract is more stable when the prospective income is higher.

\subsection{Characterization of the contract}

To derive the incentive compatibility condition, let us first consider the expected utility in anarchy. In anarchy equilibrium, $x_{i t}$ is 1 whenever $y_{i t}=1$, and $\widehat{G}_{t}-\widehat{R}_{t}-\widehat{s}_{i t}=0$ for all $i$ and $t$. In words, people would pursue socially harmful private gains (e.g. stealing others' belongings) whenever they have a chance, and there would be neither public goods nor punishment. From (2), the value of anarchy can be easily calculated as

$$
V_{A}=\sum_{t=1}^{\infty} \beta^{t-1} E\left(y_{i t}\right)=\frac{\mu}{1-\beta} .
$$

As noted earlier, this is the lower bound of the continuation value for the punished. On the other hand, the expected value of the social contract is:

$$
V_{C}=\sum_{t=1}^{\infty} E \beta^{t-1}\left(\widehat{G}_{t}-\widehat{R}_{t}\right)=\frac{\widehat{\gamma}(\underline{x}) p E\left[g\left(z_{t}\right)\right]-(1-p) E\left(\widehat{R}_{t}\right)}{1-\beta}
$$

When not knowing the tax revenue $z_{t}$, the expected value of the input for the public project is $E\left[g\left(z_{t}\right)\right]$, and if it succeeds, each citizen benefits as much as $\widehat{\gamma} E\left[g\left(z_{t}\right)\right]$. When it fails, the citizens should replace the politician, which costs $E\left(\widehat{R}_{t}\right)$. For the social contract to be sustained as an equilibrium, the individuals must find it optimal to pay the tax. So, the incentive compatibility constraint for individual $i$ with $y_{i t}=1$ is

$$
\begin{aligned}
& \widehat{\gamma} p E\left[g\left(z_{t}\right) \mid y_{i t}=1\right]-(1-p) E\left(\widehat{R}_{t}\right)+\beta V_{C} \\
\geq & 1+\widehat{\gamma} p E\left[g\left(z_{t}\right) \mid y_{i t}=1\right]-(1-p) E\left(\widehat{R}_{t}\right)+\beta\left[\phi V_{P}+(1-\phi) V_{C}\right]
\end{aligned}
$$


where $\widehat{\gamma} p E\left[g\left(z_{t}\right) \mid y_{i t}=1\right]$ is the conditional expected utility of the public goods. This differs from the unconditional utility $\widehat{\gamma} p E\left[g\left(z_{t}\right)\right]$ because $E\left[y_{t} \mid y_{i t}=1\right]$ is greater than the unconditional expectation $E\left[y_{t}\right]=\mu$. The LHS of the inequality is the expected utility for the citizen who pays the tax (i.e. $x_{i t}=0$ ), while the RHS is the utility of whom does not (i.e. $x_{i t}=1$ ). The net public benefit $\widehat{\gamma} p E\left[g\left(z_{t}\right) \mid y_{i t}=1\right]-(1-p) E\left(\widehat{R}_{t}\right)$ is given to the citizen regardless of what she does. If she evades the tax, she immediately enjoys the benefit ( 1 on the RHS), and such misbehavior is detected with probability $\phi$, in which case the continuation value drops to $V_{P}$, the expected utility for the punished. The IC constraint can be simplified as

$$
1 \leq \beta \phi\left(n_{E}\right)\left(V_{C}-V_{P}\right)
$$

The LHS is the utility from consuming the additional income, whereas the RHS is the expected cost of tax evasion. To see how this constraint works within a working social contract, let us assume that the politician can be perfectly controlled if sufficiently many citizens monitor her, i.e. $\psi\left(n_{I}\right)=1$ if $n_{I} \geq c_{I}$, and 0 otherwise. I assume that $c_{I}$ is small enough for "working" social contract with $n_{I}=c_{I}$ to exist. With this perfect monitoring technology, whenever $n_{I} \geq c_{I}$, the wage for the politician $w(z)$ must be zero for every $z$.

The social contract which maximizes the expected value of citizenship $V_{C}$ should satisfy constraint (5) as equality. Otherwise, we can slightly reduce $n_{E}$, keeping (5) held, and increase the number of citizens working in the private sector. This modification increases the tax revenue, and also the expected amount of public good provided. And, by maximum punishment principle, $V_{P}$ must be as low as possible, so $V_{P}=V_{A}$. In such a contract, since everybody working in the private sector pays the tax and no wage is given to the politician, the expected input for the public project is

$$
E\left[g\left(z_{t}\right)\right]=n_{P} \mu=\left(1-n_{E}-n_{I}\right) \mu
$$

Furthermore, because there is no reason to replace the perfectly controlled politician, the expected replacement cost $E\left(\widehat{R}_{t}\right)$ is zero for every period. Therefore, the optimal social contract is characterized by

$$
\begin{aligned}
n_{I}^{*} & =c_{I} ; w\left(z_{t}\right)=0 ; \\
1 & =\beta \phi\left(n_{E}^{*}\right)\left(V_{C}-V_{A}\right) .
\end{aligned}
$$

In the following subsections, I examine (i) how the optimal level of $n_{E}^{*}$ responds to changes in $c_{I}$ and $\underline{x}$; (ii) what the effect of prospective wealth on the stability of the contract is. 


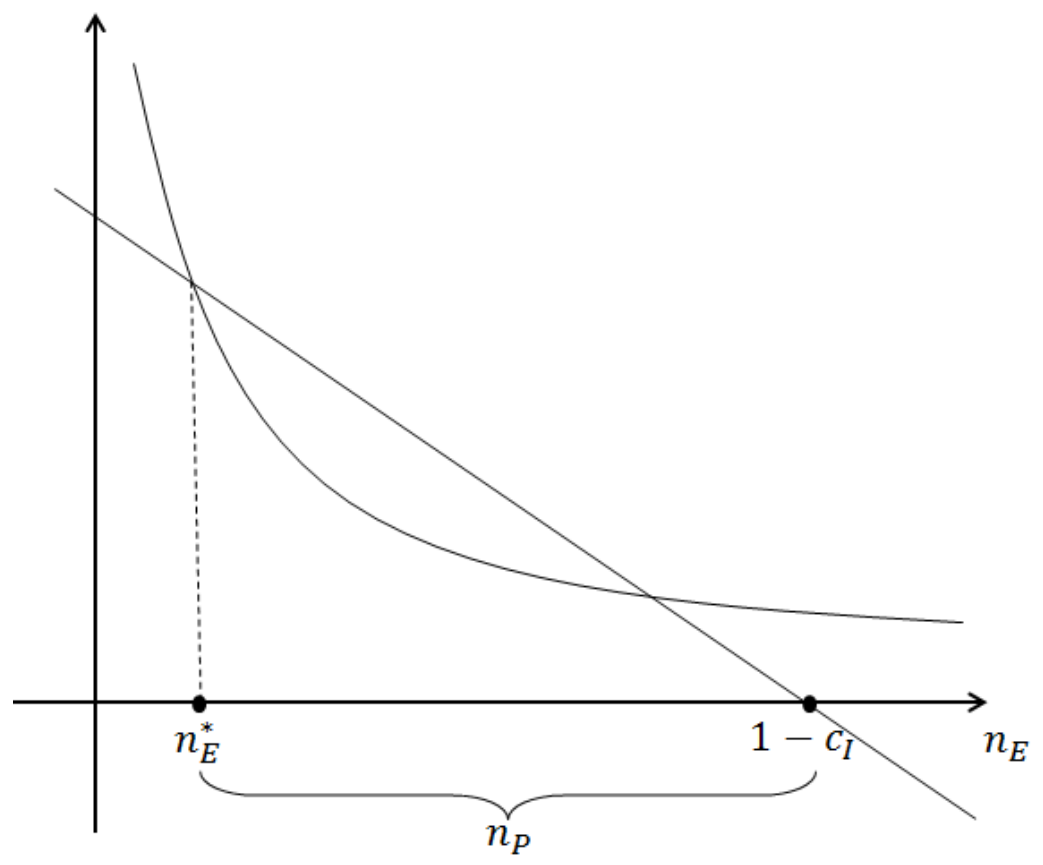

Figure 1: Incentive Compatibility Constraint for Self-Government

\subsection{The cost of self-control}

The IC constraint can be rewritten as

$$
\left(1-n_{E}^{*}-c_{I}\right) \mu \widehat{\gamma}(\underline{x}) p=\frac{1-\beta}{\beta \phi\left(n_{E}^{*}\right)}+\mu
$$

which is depicted in Figure 1. The LHS is the downward sloping line, and the RHS is the convex curve. Among the two intersections, $V_{C}$ is greater in the left one. If there is no intersection at all, there does not exist a "working" social contract.

From the figure, it is apparent that the equilibrium monitoring cost $n_{E}^{*}$ increases as the degree of agency problem of the office holder $c_{I}$ increases. The intuition is straightforward. As the agency cost on the politician's side becomes higher, the effective size of the public project $n_{P}$ gets smaller, which in turn reduces the value of being a citizen. To incentivise the people, the republic must increase its monitoring capacity $\phi\left(n_{E}\right)$.

Interestingly, when the number of people working in EMA goes up, it further reduces the effective size of the public project. In other words, the productivity of the public project decreases now due to the problem on the citizens' side. This change makes people less willing to pay the tax, so more resources should be spent to investigate the citizens' account. The chain 
of reactions continues until the change in $n_{E}$ shrinks down to zero. This positive feedback is strongest when the line and the curve are nearly tangent. So, when a country is suffering severe agency problems, a small improvement from either side can mitigate the problem substantially. On the other hand, when the public sector is already working efficiently, a small improvement in either side would not trigger an extensitve chain reaction.

Because MRS $\widehat{\gamma}(\underline{x})$ is increasing in $\underline{x}$, in other words, people value the public good more when they have more for private consumption, $n_{E}^{*}$ decreases as $\underline{x}$ goes up. Intuitively, as the average level of citizens' wealth goes up, the citizens find opportunities to pursue private economic gains againt the public welfare less attractive due to decreasing marginal utility of private consumption. Thus, the state now can save a portion of resources which were used for citizens' self-regulation. This again triggers the positive feedback mechanism described above. The discussion so far is summarized in the following proposition.

Proposition 1 The optimal monitoring cost $n_{E}^{*}$ decreases as (i) the executive becomes more accountable (i.e. $c_{I}$ goes down) and/or (ii) the wealth of the citizens grows larger (i.e. $\underline{x}$ goes up). The size of the response might be greater in countries which have more inefficient public sectors (i.e. when $n_{E}$ is large).

The proposition should be taken with caution. After all, what the optimal social contract characterizes is an upper bound, a necessary condition for a country to build a more efficient public sector. Economic development might be a necessary condition, but not a sufficient one. It does not mean either that there will always be strong positive feedbacks with respect to the public sector efficiency. The feedback mechanism may or may not be realized. What the positive feedback demonstrated here really means would be that a small improvement of public projects creates room for further improvement, and inefficiencies invite more inefficiencies.

\subsection{Stability of the contract}

The logic developed above sheds light on the stability of political regimes, too. Let us first define dismantlement of a social contract. Regard a social contract dismantled by a shock if due to the change, the participants of the contract come to prefer not-paying-tax to paying it, i.e. if the IC constraint cannot be satisfied within the contract. Graphically, if there is no intersection between the line and the curve in Figure 1, the polity is coded as dismantled. Let us assume that once a contract is dismantled, an anarchy prevails later on.

To define relative stability of social contracts, consider two countries, $A$ and $B$, with different steady-state wealth levels, $\underline{x}^{A}$ and $\underline{x}^{B}$. Now suppose the baseline income $\underline{x}_{t}$ is subject 
to a negative shock. In particular, suppose $\underline{x}_{t}$ drops to $\underline{x}^{0}$ at period $s$, is recovered to $\underline{x}^{N}$ (for $N \in\{A, B\})$ in the next period and remain there later on, i.e. $\underline{x}_{s}=\underline{x}^{0}$, and $\underline{x}_{s+1}=\underline{x}_{s+2}=$ $\ldots=\underline{x}^{N}$ with $\underline{x}^{N}>\underline{x}^{0}$ for both $N$. If a social contract $A$ is dismantled by this negative shock, while the other is not, we can say that contract $B$ is more stable than $A$ with respect to $\underline{x}^{0}$. On the other hand, if both states take to pieces, or if both of them remain as ones, I would say that they are equally (un)stable with respect to $\underline{x}^{0}$.

When the negative shock hits the economies, citizens with greater prospective wealth are likely to value the contract more. Thus, citizens in richer countries would find it easier to sacrifice the current consumption even in hard times. The following proposition captures this intuition.

Proposition 2 If steady-state wealth level $\underline{x}^{A}$ is greater than or equal to $\underline{x}^{B}$, social contract $A$ is more stable than or equally (un) stable to contract $B$ with respect to any $\underline{x}^{0}$.

Proof. Here, I show that the IC constraint in period $s$ can be more easily satisfied when the prospective wealth level is larger. To avoid confusion, I derive the IC constraint from the original utility form in (1).

For country $N \in\{A, B\}$, from period $s+1$ and on, the expected value of citizenship $W_{C}^{N}$ and the value of anarchy $W_{A}^{N}$ are respectively

$$
\begin{aligned}
W_{C}^{N} & =\frac{u\left(\underline{x}^{N}\right)+\gamma p\left(1-n_{E}^{N}-c_{I}\right) \mu}{1-\beta} ; \\
W_{A}^{N} & =\frac{u\left(\underline{x}^{N}\right)+\left[u\left(\underline{x}^{N}+1\right)-u\left(\underline{x}^{N}\right)\right] \mu}{1-\beta}
\end{aligned}
$$

where $n_{E}^{N}$ is the optimal level of monitoring cost in contract $N$, which has been derived above. In considering the IC constraint, let us take $\phi\left(n_{E}\right)$, the monitoring capacity in period $s$ as given for a moment. Provided that all the other people in country $N$ pay the taxes, the IC constraint for the citizens with $y_{i s}=1$ when the income drops to $\underline{x}^{0}$ is

$$
\begin{aligned}
& u\left(\underline{x}^{0}\right)+\gamma p E\left[g\left(z_{s}\right) \mid y_{i s}=1\right]+\beta W_{C}^{N} \\
\geq & u\left(\underline{x}^{0}+1\right)+\gamma p E\left[g\left(z_{s}\right) \mid y_{i s}=1\right]+\beta\left[\phi W_{A}^{N}+(1-\phi) W_{C}^{N}\right]
\end{aligned}
$$

which can be simplified as

$$
u\left(\underline{x}^{0}+1\right)-u\left(\underline{x}^{0}\right) \leq \beta \phi \mu\left\{\gamma p\left(1-n_{E}^{N}-c_{I}\right)-\left[u\left(\underline{x}^{N}+1\right)-u\left(\underline{x}^{N}\right)\right]\right\} .
$$

Recall that $n_{E}^{N}$ is decreasing in $\underline{x}^{N}$ as shown in Proposition 1. Thus, for any given monitoring capacity $\phi$, the RHS is increasing in $\underline{x}^{N}$, which implies that the maximized value of the RHS 
with respect to $\phi$ is also increasing in $\underline{x}^{N}$. Therefore, the IC constraint for contract $A$ is more easily satisfied than that for contract $B$, if $\underline{x}^{A}$ is greater than or equal to $\underline{x}^{B}$.

Przeworski (2005) shows that economic development can enhance the stability of political regimes. His argument focuses on the incentive for political losers to conform democratic rules. Because non-institutionalized political conflicts such as revolution or civil war destroy economic institutions and assets, they are more costly in economically better-developed societies. Proposition 2 provides a different perspective on the effect of economic development on the stability of political regime. It states that a polity is more resilient to negative shocks when the steady-state economic wealth is greater. What really matters here is the future income instead of the current income, which suggests that other things being equal, a society with a higher economic growth rate is likely to have a more stable political system.

\section{People as Principals}

In this section, I first characterize the optimal social contract in a more flexible setup, and then investigate how the optimal level of checks-and-balances measured by $n_{I}$ responds to a change in the level of wealth. In particular, I explicitly consider the office holder's incentive by assuming $\psi(\cdot) \in[0,1)$ is a twice-differentiable, increasing, strictly concave function. I further assume that $\psi(0)=0$, and $\lim _{n \rightarrow 0} \psi^{\prime}(n)=\infty$. By doing so, I analyze the incentives of citizens as principals. In this section, I assume $\underline{x}_{t}=\underline{x}$ for all $t$.

\subsection{Chracterization of the contract}

Note first that because the monitoring technology is imperfect $(\psi<1)$, the politician must be given a positive rent, i.e. $w(z)>0$ for some $z$. I assume that the wage for the executive comes from the tax revenue $z_{t}$. Given the wage schedule $w(\cdot)$, the value of holding the office and not diverting the public funds is

$$
V_{O}=E\left[w\left(z_{t}\right)\right]+\beta p V_{O}=\frac{E\left[w\left(z_{t}\right)\right]}{1-\beta p} .
$$

Since with probability $1-p$, the project fails and the officer is replaced, the effective discount factor for politicians is $\beta p$. In any contract without waste of resources,

$$
w(z)+g(z)=z, \text { for all } z .
$$

In other words, the tax revenue should be distributed between the office holder and the citizens. If more resources are allocated to the politician, the value for being a citizen which increases 
in $E[g(z)]$ will be reduced, and as shown in the previous section, the republic should spend more resources in monitoring its citizens. Thus, in the optimal social contract, the rent must be minimized subject to the incentive compatibility constraint for the executive officer.

Given the replacement strategy of the citizens $\Lambda$, that is "replace the officer if $G_{t}<\gamma g\left(z_{t}\right)$ ", the expected value of diverting $T_{t}>0$ of public fund is $w\left(z_{t}\right)+(1-\psi) T_{t}$. Here, $T_{t}$ is discounted by $1-\psi$ because the diverted fund is impounded with probability $\psi$. From this, it is apparent that diverting a little bit of the public fund is a strategy dominated by diverting the entire fund. So, the relevant IC constraint is

$$
w\left(z_{t}\right)+\beta p V_{O} \geq w\left(z_{t}\right)+(1-\psi) g\left(z_{t}\right)
$$

The RHS is the expected value of appropriating the entire fund for private benefit, i.e. the value with $T_{t}=z_{t}-w\left(z_{t}\right)=g\left(z_{t}\right)$. The constraint can be rewritten as

$$
g\left(z_{t}\right) \leq \min \left\{z_{t}, \frac{\beta p V_{O}}{1-\psi\left(n_{I}\right)}\right\}=\min \left\{z_{t}, \frac{\beta p E\left[z_{t}-g\left(z_{t}\right)\right]}{\left[1-\psi\left(n_{I}\right)\right](1-\beta p)}\right\}
$$

From this, we can see that the input $g(z)$ is non-decreasing in $n_{I}$. That is, as more resources are invested in monitoring the executive, the citizens can reduce the rent, and increase the input for public good production to generate a greater public benefit.

The optimal social contract maximizes the expected utility of citizens, while making the individuals pay taxes and the politician not divert the fund illegitimately. So, it solves

$$
\max _{n_{I}, n_{E}, g} V_{C}
$$

subject to (5) and (6). As Inada conditions being assumed, there would exist an interior solution for this program if the monitoring technologies are efficient enough, i.e. $\phi\left(n_{E}\right)$ and $\psi\left(n_{I}\right)$ increase fast enough. Under the assumption that the program has a proper interior solution, the following proposition characterizes the optimal social contract.

Proposition 3 Suppose there exists an interior solution for the social contract problem. Then, the optimal composition of the government $\left(n_{E}^{*}, n_{I}^{*}\right)$ is characterized by

$$
\begin{aligned}
\frac{1-\psi\left(n_{I}^{*}\right)}{\psi^{\prime}\left(n_{I}^{*}\right)} \mu & =n_{P}^{*} \mu-\frac{1}{\widehat{\gamma}(\underline{x}) p}\left[\frac{1-\beta}{\beta \phi\left(n_{E}^{*}\right)}+(1-p) \widehat{R}(\underline{x})+\mu\right] \\
\frac{1}{\widehat{\gamma}(\underline{x}) p}\left[\frac{1-\beta}{\beta \phi\left(n_{E}^{*}\right)}+(1-p) \widehat{R}(\underline{x})+\mu\right] & =\int_{0}^{\Upsilon / n_{P}^{*}} n_{P}^{*} y_{t} d F+\left[1-F\left(\frac{\Upsilon}{n_{P}^{*}}\right)\right] \Upsilon
\end{aligned}
$$


where $\Upsilon=\frac{\beta p}{1-\beta p} \frac{\mu}{\psi^{\prime}\left(n_{I}^{*}\right)}$. And, the optimal compensation scheme for the politician is

$$
g^{*}\left(z_{t}\right)=\min \left\{z_{t}, \frac{\beta p\left[n_{P}^{*} \mu-\frac{1}{\widehat{\gamma}(\underline{x}) p}\left(\frac{1-\beta}{\beta \phi\left(n_{E}^{*}\right)}+(1-p) \widehat{R}(\underline{x})+\mu\right)\right]}{\left[1-\psi\left(n_{I}^{*}\right)\right](1-\beta p)}\right\} .
$$

Proof. In the previous section, I show that (5) must hold as equality. Similarly, (6) must be binding in the optimal social contract, otherwise by decreasing $w$, one can increase the public good provision $g$ at least for some $z_{t}$, which will increase $V_{C}$. From (4), it is apparent that maximizing $V_{C}$ is equivalent with maximizing $E\left[g\left(z_{t}\right)\right]$. From (4) and (5), one can derive the following formular:

$$
E\left[g\left(z_{t}\right)\right]=\frac{1}{\widehat{\gamma} p}\left(\frac{1-\beta}{\beta \phi}+(1-p) \widehat{R}+\mu\right)
$$

Using (6), (9) and the fact that $z_{t}=n_{P} y_{t}$, one can rewrite $E\left[g\left(z_{t}\right)\right]$ as

$$
\begin{aligned}
E\left[g\left(z_{t}\right)\right] & =E\left[\min \left\{n_{P} y_{t}, \Gamma\right\}\right] \\
& =\int_{0}^{\Gamma / n_{P}} n_{P} y_{t} d F\left(y_{t}\right)+\left[1-F\left(\frac{\Gamma}{n_{P}}\right)\right] \Gamma
\end{aligned}
$$

where

$$
\Gamma=\frac{\beta p\left[n_{P} \mu-\frac{1}{\hat{\gamma} p}\left(\frac{1-\beta}{\beta \phi}+(1-p) \widehat{R}+\mu\right)\right]}{(1-\psi)(1-\beta p)}
$$

Note that the RHS of (10) is strictly increasing in $\Gamma$, i.e. $V_{C}$ is a monotone transformation of $\Gamma$. Therefore, an alternative representation of the optimization problem is:

$$
\max _{n_{E}, n_{I}} \Gamma
$$

subject to

$$
\frac{1}{\widehat{\gamma} p}\left(\frac{1-\beta}{\beta \phi}+(1-p) \widehat{R}+\mu\right)=\int_{0}^{\Gamma / n_{P}} n_{P} y_{t} d F\left(y_{t}\right)+\left[1-F\left(\frac{\Gamma}{n_{P}}\right)\right] \Gamma .
$$

The equality constraint is obtained by combining the IC constraints. The first-order conditions with respect to $n_{E}$ and $n_{I}$ together generate condition (7). Condition (8) is the equality constraint.

There might exist more than one solution for the system of equations (7) and (8) as we have seen in Figure 1. In such a case, the one with smallest $n_{E}$ is the solution of the program. Using the result derived here, in the following subsection, I investigate how the society's wealth relates to the structure of the government. 


\subsection{Social demand for checks-and-balances}

As shown in the previous section, the optimal level of $n_{E}$ decreases as the baseline income $\underline{x}$ grows larger. Smaller $n_{E}$ means greater $n_{P}$. That is, as the agency cost decreases, the effective size of the public project becomes larger. The following proposition states that people as principals are more willing to make investment in monitoring the executive when the size of project is greater. For clearer exposition, I assume for a moment that the political system is well-institutionalized, so replacing a politician is costless (i.e. $R=0$ ). I will discuss the effects of replacement cost on the optimal contract in Section 6.

Proposition 4 The social demand for checks-and-balances measured by $n_{I}^{*}$ becomes stronger as the society's wealth increases.

Proof. Recall that $\widehat{R}(\underline{x})=0$ when $R=0$. Differentiating (7) and (8) with respect to $\widehat{\gamma}(\underline{x})$, we obtain

$$
\begin{aligned}
-\frac{(1-\psi) \psi^{\prime \prime} \mu}{\left(\psi^{\prime}\right)^{2}} \frac{\partial n_{I}^{*}}{\partial \widehat{\gamma}}+\left(\mu-\frac{1-\beta}{\widehat{\gamma} p \beta} \frac{\phi^{\prime}}{\phi^{2}}\right) \frac{\partial n_{E}^{*}}{\partial \widehat{\gamma}} & =\frac{1}{\widehat{\gamma}^{2} p}\left(\frac{1-\beta}{\beta \phi}+\mu\right) \\
-\frac{(1-F) \psi^{\prime \prime}}{\left(\psi^{\prime}\right)^{2}} \frac{\beta p \mu}{1-\beta p} \frac{\partial n_{I}^{*}}{\partial \widehat{\gamma}}+\frac{1-\beta}{\widehat{\gamma} p \beta} \frac{\phi^{\prime}}{\phi^{2}} \frac{\partial n_{E}^{*}}{\partial \widehat{\gamma}} & =-\frac{1}{\widehat{\gamma}^{2} p}\left(\frac{1-\beta}{\beta \phi}+\mu\right)
\end{aligned}
$$

Note first that the coefficients of $\partial n_{I}^{*} / \partial \widehat{\gamma}$ in the both equations are positive, and the RHS of (11) is positive while that of (12) is negative. Adding up these two equations, we have

$$
-\frac{\psi^{\prime \prime} \mu}{\left(\psi^{\prime}\right)^{2}}\left[1-\psi+\frac{(1-F) \beta p}{1-\beta p}\right] \frac{\partial n_{I}^{*}}{\partial \widehat{\gamma}}+\mu \frac{\partial n_{E}^{*}}{\partial \widehat{\gamma}}=0,
$$

which shows that $n_{I}$ and $n_{E}$ move to the opposite directions in response to a change in $\widehat{\gamma}$. In the rest of the proof, I show that $\partial n_{I}^{*} / \partial \widehat{\gamma}>0$ and $\partial n_{E}^{*} / \partial \widehat{\gamma}<0$. First, let us differentiate $\Gamma$, the objective of the program considered in the proof of Proposition 3, with respect to $n_{E}$ to derive the following relationship.

$$
\mu-\frac{1-\beta}{\widehat{\gamma} p \beta} \frac{\phi^{\prime}}{\phi^{2}}=-\frac{\beta p}{(1-\psi)(1-\beta p)} \frac{\partial \Gamma}{\partial n_{E}}
$$

Note that the LHS of the equation is the coefficicent of $\partial n_{E}^{*} / \partial \widehat{\gamma}$ in (11). If $\partial \Gamma / \partial n_{E}$ is negative, we can increase $\Gamma$ by reducing $n_{E}$, which means too much resource is spent in monitoring the citizens. So in the "working" optimal contract, $\partial \Gamma / \partial n_{E}$ must be positive, which implies that the coefficient of $\partial n_{E}^{*} / \partial \widehat{\gamma}$ must be negative. Given a negative coefficient of $\partial n_{E}^{*} / \partial \widehat{\gamma}$, the LHS of 


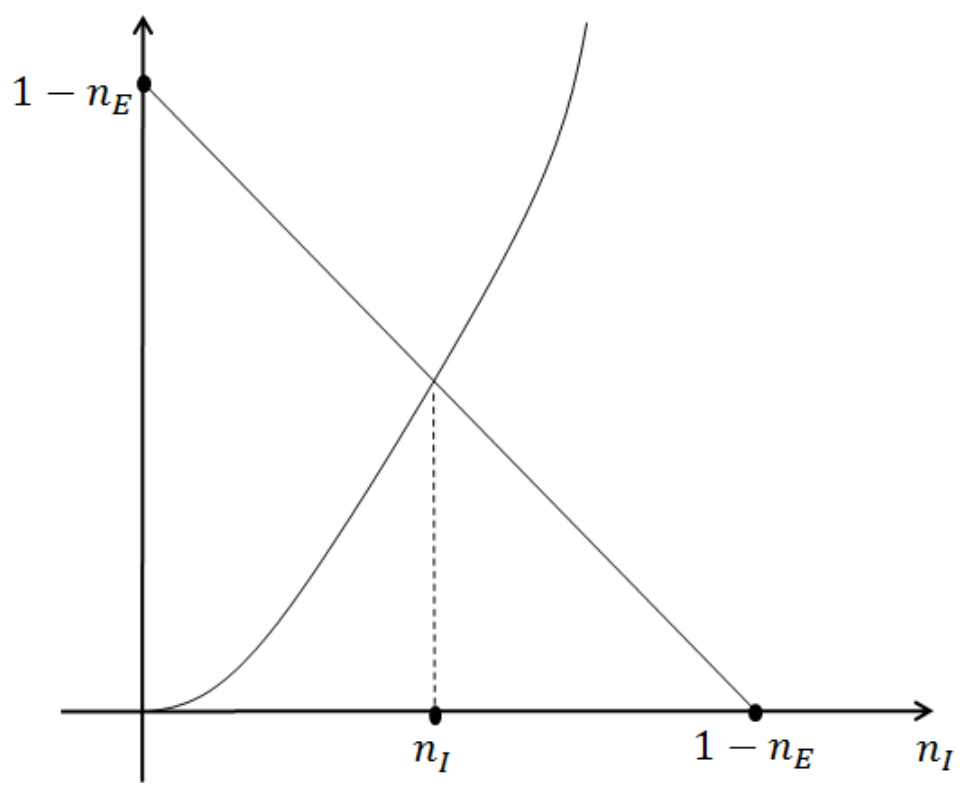

Figure 2: Optimal Checks-and-Balances

(11) cannot be positive if $\partial n_{I}^{*} / \partial \widehat{\gamma}<0$ and $\partial n_{E}^{*} / \partial \widehat{\gamma}>0$. Thus, $\partial n_{I}^{*} / \partial \widehat{\gamma}>0$ and $\partial n_{E}^{*} / \partial \widehat{\gamma}<0$. Since $\widehat{\gamma}(\underline{x})$ is increasing in $\underline{x}, \partial n_{I}^{*} / \partial \underline{x}>0$ and $\partial n_{E}^{*} / \partial \underline{x}<0$.

In the optimal contract, the resources spent in monitoring the citizes $n_{E}$ decreases as the wealth $\underline{x}$ increases as shown in the previous section. As the level of baseline income is enhanced, the marginal utility of private consumption becomes smaller, and consequently, the agency problem on the individuals' side becomes less significant. Thus, less amount of resource is required to incentivize the individuals. By reducing the resources spent in monitoring the private sector, the expected payoff for the citizens can be improved either by generating more taxable income (i.e. increasing $n_{P}$ ) and/or by monitoring the politician more tightly (i.e. increasing $n_{I}$ ). It turns out that at the optimum, the citizens decide to reduce the rent by enhancing the probability of detecting potential misuse of the public fund.

To understand the result more clearly, let us consider the following simplified problem. Suppose that once the taxes are collected, $1-\bar{\psi}\left(n_{I}\right)$ fraction of the revenue should be granted to the executive as a rent where $\bar{\psi}<1$ is a twice-differentiable, increasing, strictly concave function. So, the share of tax revenue invested in the public project is $\bar{\psi}\left(n_{I}\right)$. Then, the optimal contract should solve

$$
\max _{n_{I}} \bar{\psi}\left(n_{I}\right)\left(1-n_{I}-n_{E}\right)
$$


For a given $n_{E}$, the original social contract problem is very similar with this simplified one. ${ }^{11}$ By reducing $n_{I}$, the citizens can increase the effective size of the project, but have to allow a greater rent to the executive. The solution of this problem satisfies

$$
\frac{\bar{\psi}\left(n_{I}\right)}{\bar{\psi}^{\prime}\left(n_{I}\right)}=1-n_{I}-n_{E}
$$

which is depicted in Figure 2. The upward sloping curve represents the LHS of the equation, and the downward sloping line does the RHS. As $n_{E}$ decreases, that is, as the effective size of the project increases, the citizens prefer to have a greater share of the revenue be invested in the public project. To do so, they should exert more effort in checking the office holder. This is what happens in relation with the executive of the public project when the agency problem on people's side is mitigated, i.e. when $\gamma, \underline{x}$ or $p$ increases.

This proposition should not be understood as that poor countries prefer a less accountable government. As shown in the previous section, regardless of their wealth level, citizens prefer more accountable government. What the proposition really means is that richer societies would be more willing to spend a substantial amount of resources in monitoring and disciplining the political elites.

The analysis thus far shows that the agency problems on the two sides aggravate each other. Citizens in less developed economies are exposed to more temptation to pursue private economic gains against the public welfare. To incentivize them, more resources should be spent in keeping the law and order and investigating the private sector, and consequently, relatively less resources are spent in deciplining the political elites. ${ }^{12}$ This means that the government provides public goods in a less efficient manner, and inefficient public sector reduces citizens' willingness to sacrifice private economic benefits. In this way, the overall agency problems becomes disproportionately more severe in less developed countries, and citizens suffer poorquality public sector.

\footnotetext{
${ }^{11}$ The objective function of the original problem is in the form of $\left(1-n_{I}-n_{E}\right) /\left[1-\psi\left(n_{I}\right)\right]$ rather than $\psi\left(n_{I}\right)\left(1-n_{I}-n_{E}\right)$. See $\Gamma$ in the proof of Proposition 3. However, the comparative statics with respect to $n_{E}$ in these two problems are qualitatively same.

${ }^{12}$ In the formal model, I assume that the effects of $n_{I}$ and $n_{E}$ are perfectly separable. However, in reality, a larger bureaucracy and a stronger state apparatus may expand room for rent-seeking behavior. For example, the replacement cost $R$ might be a increasing function of $n_{E}$, or $\psi\left(n_{I}, n_{E}\right)$ might be increasing in the first argument, but decreasing in the second one. In this case, an increase in $n_{E}$ would immediately make the government less accountable. I discuss such possibilities in Section 6 .
} 


\section{Economic Growth in Self-Government Model}

Thus far, I have considered on the optimal contract in static enviornments. The analysis has shown that the agency problem on people's side could affect the structure and quality of public sector. In this section, I combine the mechanism identified above and the one widely studied in the literature, namely the quality of public sector affects the economic performance of the country, together to illustrate a dynamic feedback mechanism. In particular, I show that the imperfection in law enforcement can generate multiple steady-state equilibria in a simple growth model. It suggests that economic development driven by exogenous factors might help developing countries improve the quality of their public sectors.

\section{$5.1 \quad$ Model}

Consider a simple neo-classical growth model with one productive factor, capital. To capture the idea that the quality of public sector affects the economic performance of the country in a parsimonious way, I assume that the productivity of the economy depends upon the level of public goods provided in the economy. ${ }^{13}$ Specifically, individuals have an access to the same technology for producing private goods, which is given as

$$
\underline{y}_{i t}=G_{t} k_{i t}^{\alpha}
$$

where $\underline{y}_{i t}$ is the income of individual $i$ from the productive factor $k_{i t}, \alpha$ is smaller than 1 , and the productivity $G_{t}$ is determined by the public investment in the previous period:

$$
G_{t+1}=\underline{g}+\gamma \int\left(y_{i t}-x_{i t}\right) d i
$$

where $\underline{g}$ is exogenously given public goods. As before, $y_{i t}$ is the exogenously given taxable income, and $x_{i t}$ is individual's decision with regard to paying the tax. So, $\int\left(y_{i t}-x_{i t}\right) d i$ is the tax revenue. The capital good is convertible to the conumption good by 1-to-1 technology, and vice versa.

To keep the model simple, I abstract from the agency problem of the executive officer by assuming that she is perfectly monitored (i.e. $\psi=1$ ) without incuring any cost. And I further assume that every individual is given one unit of taxable endowment in each period (i.e. $y_{i t}=1$ for all $i$ and $t$ ), and the public project always succeeds (i.e. $p=1$ ). The agency problem is introduced in a less subtle way: the capacity to punish those who breach the contract is limited

\footnotetext{
${ }^{13}$ A number of previous studies have employed similar assumptions. See for example Acemoglu (2005) and references therein.
} 
(i.e. $\phi_{t}<1$ ), and the disutility of punishment is finite (i.e. $S_{t}<\infty$ ). In other words, here I assume that if everybody decides not to pay the tax, only $\phi_{t}$ of citizen will be punished, even though the government knows that nobody paid the tax. To make the model as consistent with the model in the previous sections as possible, let us assume that the lower bound of the punishment severity does not change, i.e. $S_{t}=S$ for all $t$. But, it is natural to allow the capacity to punish to increase as the country is economically more developed. In particular, let the capacity be $\phi_{t}=\phi\left(K_{t}\right)$ where $\phi(\cdot)$ is a non-decreasing function which does not depend on the number of people working in EMA $n_{E}$ but on $K_{t}=\int k_{i t} d i$ the aggregate level of capital stock. ${ }^{14}$ The probability to get caught and punished is

$$
\widehat{\phi}_{t}=\min \left\{1, \frac{\phi_{t}}{\int x_{i t} d_{i}}\right\}
$$

where $\int x_{i t} d_{i}$ is the measure of those who do not pay the tax. Under theses assumptions, everybody will work in the private sector. So, the aggregate taxable endowment $y_{t}=\int y_{i t} d i$ is 1 for all $t$. If nobody pays the tax, the aggregate productivity $G_{t}$ is $\underline{g}$, and the probability to be punished $\widehat{\phi}_{t}$ is simply $\phi_{t}$. If everybody pays it, on the other hand, $G_{t}=\underline{g}+\gamma$, and $\widehat{\phi}_{t}=1$. The citizens are ex-ante identical, i.e. $k_{i 1}=k_{1}$ for all $i$.

Let $\mathbf{x}_{i}$ be the vector $\left(x_{i 1}, x_{i 2}, x_{i 3}, \ldots\right)$ and $\mathbf{k}_{i}$ be $\left(k_{i 2}, k_{i 3}, k_{i 4}, \ldots\right)$. Then, an equilibrium in this model is a list of the sequence of public goods $\left\{G_{t}\right\}_{t=1}^{\infty}$ and the punishment capacities $\left\{\phi_{t}\right\}_{t=1}^{\infty}$, and the individuals' strategies $\left\{\left(\mathbf{x}_{i}, \mathbf{k}_{i}\right)\right\}_{i \in[0,1]}$ such that given the initial capital stock $k_{i 1}$, the sequence of public goods, the punishment capacities and the others' strategies $\left\{\left(\mathbf{x}_{j}, \mathbf{k}_{j}\right)\right\}_{j \neq i}$, individual $i$ maximizes her expected utility by choosing $\left(\mathbf{x}_{i}, \mathbf{k}_{i}\right)$ :

$$
\max \sum_{s=0}^{\infty} E_{t} \beta^{s}\left[u\left(\underline{x}_{i, t+s}+x_{i, t+s}\right)-S \widehat{\phi}_{t+s} x_{i, t+s}\right]
$$

subject to

$$
\begin{aligned}
\underline{x}_{i t}+k_{i, t+1} & \leq \underline{y}_{i t}+(1-\delta) k_{i t} \\
x_{i t} & \in\{0,1\}
\end{aligned}
$$

where $\delta \in(0,1]$ is the depreciation rate of capital.

\footnotetext{
${ }^{14} \mathrm{~A}$ more realistic assumption would be that $\phi_{t}$ depends on the government budget in period $t$ which is determined by the cummulative amount of tax revenue until $t$. However, since $\phi_{t}$ is taken as given by individuals, how exactly it grows does not matter from the perspective of the citizens. A sufficient condition for the result derived below is that in equilibrium, $\phi_{t}$ does not decrease when the economy gets more developed.
} 


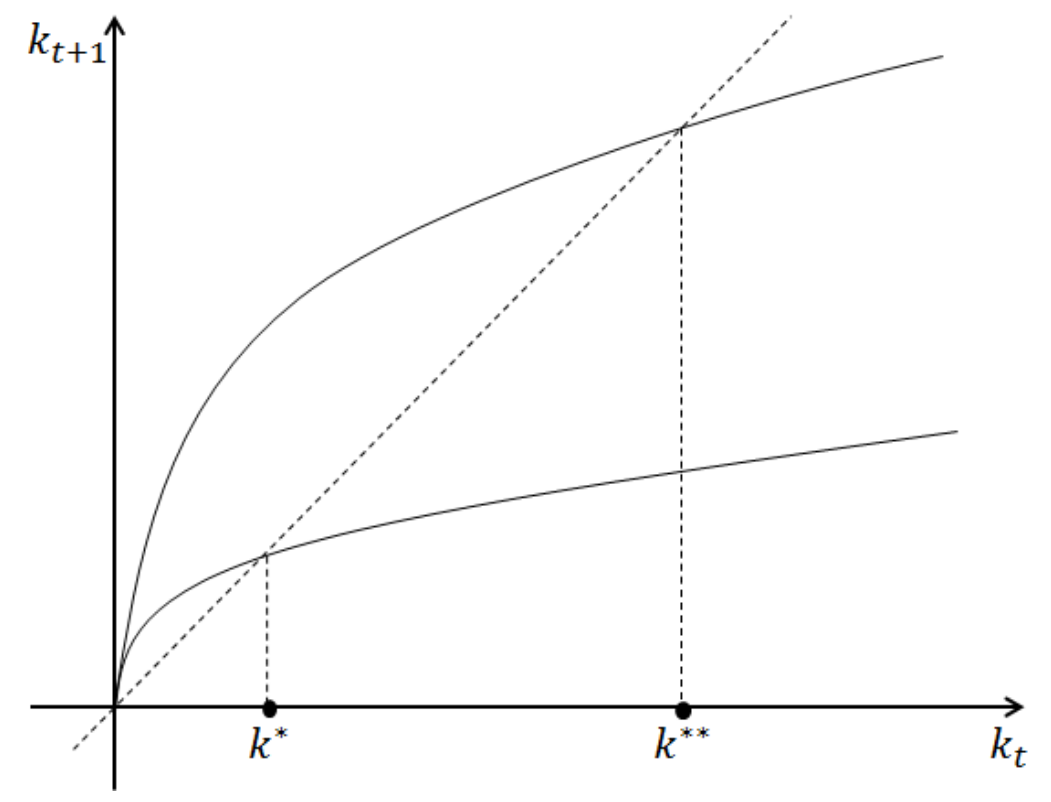

Figure 3: Steady-States with Different Aggregate Productivities

It is noteworthy that unlike in the model considered in the previous sections, the baseline income here is determined by individuals' investment decision, as $\underline{x}_{i t}=G_{t} k_{i t}^{\alpha}+(1-\delta) k_{i t}-k_{i, t+1}$. Depending on parameter values, there may exist several equilibria with different levels of public good provision. Below, I show that if $S \phi$ is in intermediate range, there exist at least two steady-state equilibria in one of which nobody pays the tax, whereas in the other, everybody pays.

\subsection{Poverty trap}

Let us first consider the following dynamic programing problems.

$$
V^{*}\left(k_{i t}, G_{t}\right)=\max _{k_{i, t+1}}\left\{u\left(\underline{x}_{i t}+1\right)+\beta V^{*}\left(k_{i, t+1}, G_{t+1}\right)\right\}
$$

and

$$
V^{* *}\left(k_{i t}, G_{t}\right)=\max _{k_{i, t+1}}\left\{u\left(\underline{x}_{i t}\right)+\beta V^{* *}\left(k_{i, t+1}, G_{t+1}\right)\right\}
$$

where $\underline{x}_{i t}=G_{t} k_{i t}^{\alpha}+(1-\delta) k_{i t}-k_{i, t+1}$. It is straightforward to show that given a fixed productivity $G_{t}=G_{t+1}=G$, each problem generates an optimal growth path which leads to a unique steady state. Recall that the shape of utility function does not affect the steady-state 
level of capital stock, which means the above two problems generate the same steady-state capital stock if and only if the fixed productivity $G$ are same. When they are given as $\underline{g}$ and $\underline{g}+\gamma$, the steady-state capital stocks are respectively

$$
k^{*}=\left(\frac{\alpha \beta \underline{g}}{1-\beta+\beta \delta}\right)^{\frac{1}{1-\alpha}}
$$

and

$$
k^{* *}=\left(\frac{\alpha \beta(\underline{g}+\gamma)}{1-\beta+\beta \delta}\right)^{\frac{1}{1-\alpha}}
$$

which are graphically represented in Figure 3. As is apparent in the formulars, $k^{* *}$ is greater than $k^{*}$, and the gap between the two steady-state becomes greater as $\gamma$ increases. The corresponding steady-state baseline consumptions are

$$
\begin{aligned}
\underline{x}^{*} & =\underline{g}\left(k^{*}\right)^{\alpha}-\delta k^{*}, \\
\underline{x}^{* *} & =(\underline{g}+\gamma)\left(k^{* *}\right)^{\alpha}-\delta k^{* *} .
\end{aligned}
$$

To focus on non-trivial case, I assume that

$$
u\left((\underline{g}+\gamma)\left(k^{* *}\right)^{\alpha}-\delta k^{* *}\right)-u\left(\underline{g}\left(k^{* *}\right)^{\alpha}-\delta k^{* *}+1\right)>0 .
$$

This assumption implies that if the citizens are sufficiently patient, having more public good is socially desirable. ${ }^{15}$ To see this, recall first that for large enough $\beta$, the social welfare should be evaluated at the steady state. And, because $k^{* *}>k^{*}$, the assumption implies

$$
\frac{u\left((\underline{g}+\gamma)\left(k^{* *}\right)^{\alpha}-\delta k^{* *}\right)}{1-\beta}>\frac{u\left(\underline{g}\left(k^{*}\right)^{\alpha}-\delta k^{*}+1\right)}{1-\beta} .
$$

So, the steady-state expected utility level with more public goods is higher than that with less. It means if the citizens can perfectly control themselves, they would always choose to have a more public goods. The following proposition shows that even when the expected benefit is greater than the cost, the agency problem exacerbated by poverty might prevent citizens from having a higher-quality public sector, if the state apparatus is not strong enough.

Proposition 5 Suppose that for some $\underline{K} \in\left[k^{*}, k^{* *}\right]$,

$$
u\left(\underline{x}^{* *}+1\right)-u\left(\underline{x}^{* *}\right)<S \phi(\underline{K})<u\left(\underline{x}^{*}+1\right)-u\left(\underline{x}^{*}\right) .
$$

Then, there exist two steady-state equilibria with different levels of public goods provision.

\footnotetext{
${ }^{15}$ Observe that the expressions inside of $u(\cdot)$ may be negative. Let $u(x)=\lim _{\widehat{x} \rightarrow 0} u(\widehat{x})$ whenever $x$ is non-positive. Then, for large $\gamma$, the second term would be $\lim _{\widehat{x} \rightarrow 0} u(\widehat{x})$.
} 
Proof. Suppose $k_{1}=k^{*}$. Others' strategy being $\mathbf{x}_{j}=(1,1, \ldots)$ for all $j \neq i, G_{t}=\underline{g}$ for all $t$. To confirm the existence of the equilibrium with low public good provision, we just need to check the incentive to unilaterally deviate from not-paying-tax to paying-tax. Note first that with a concave utility function, changing $x_{i t}$ from time to time would be a dominated strategy, because it hinders consumption smoothing. So below, I compare the expected utilities with $\mathbf{x}_{i}=(1,1, .$.$) and \mathbf{x}_{i}=(0,0, \ldots)$. The condition $S \phi(\underline{K})<u\left(\underline{x}^{*}+1\right)-u\left(\underline{x}^{*}\right)$ implies $S \phi\left(k^{*}\right)<u\left(\underline{x}^{*}+1\right)-u\left(\underline{x}^{*}\right)$, which can be rewritten as

$$
\frac{u\left(\underline{x}^{*}+1\right)-S \phi\left(k^{*}\right)}{1-\beta}>\frac{u\left(\underline{x}^{*}\right)}{1-\beta}=\max _{k_{i, t+1}}\left\{u\left(\underline{g}\left(k^{*}\right)^{\alpha}+(1-\delta) k^{*}-k_{i, t+1}\right)+\beta V^{* *}\left(k_{i, t+1}, \underline{g}\right)\right\} .
$$

The equality is from the fact that the steady-state capital stock depends only on the expected return, which means that regardless of $x_{i t}$, the optimal investment strategy is to keep the stock as $k^{*}$. Thus, individuals have no incentive to pay the tax, which means that there does exist a steady-state equilibrium with $k_{t}=k^{*}$ for all $t$. The proof of the other half is a mirror image of the above, thus omitted.

Notice that a constant punishment capacity $\phi$ is a special case of non-decreasing capacities $\phi(K)$. So, it is clear that the result is not mainly driven by the assumption on the punishment capacity, but by the fact that sacrificing private benfits for public welfare is more painful for individuals with lower income. In this sense, this proposition shows the intuition developed in the previous section can be applied to a more dynamic setting.

The dynamic feedback mechanism that generates multiple equilibria can be described as follows. Suppose a society is given a low level of initial capital. Because its production capacity is low, so will the income of the citizens be. As we have seen in the previous sections, the cost of self-control is particularly high when income level is low. So, the governments in poor countries would fail to provide public goods such as social infrastructure, public education and health care in an efficient manner. Because such public goods are productivity-enhancing, failing to provide them enough would lower the expectations on the economy's productivity in the future. Since the expected return from private investment is low, citizens would invest little, and in the next period, will start with a low level of capital stock. Therefore, the agency costs will remain high in the consequent periods.

It is also worth mentioning that the result would hold even without the simplifying assumptions. For instance, if the executive is subject to moral hazard problem as in the previous sections, the discrepancy of the agency costs in high and low income countries would be even higher because agency problems tend to make each other worse. Thus, introducing the moral hazard of political elites would expand the parameter range where multiple equilibria exist. 


\section{Political Institutions}

\subsection{Democratization}

The discussions in previous sections paid little attention to political processes such as elections, non-institutionalized political conflicts and illegitimate suppressions. The model in Section 4, however, can provide insights regarding how political institutionalization relates to the overall efficiency of public sector. The main idea is that political institutionalization which reduces the cost to replace the executive will increase the value of citizenship, so eventually will allow public sector to be more efficiently reformed.

Proposition 6 In response to a reduction in the replacement cost $R$, the optimal level of resources spent in checks-and-balances $n_{I}^{*}$ increases, while the optimal capacity of monitoring private sector $n_{E}^{*}$ decreases.

Proof. Differentiating (7) and (8) with respect to $\widehat{R}$, we obtain

$$
\begin{aligned}
&-\frac{(1-\psi) \psi^{\prime \prime} \mu}{\left(\psi^{\prime}\right)^{2}} \frac{\partial n_{I}^{*}}{\partial \widehat{R}}+\left(\mu-\frac{1-\beta}{\widehat{\gamma} p \beta} \frac{\phi^{\prime}}{\phi^{2}}\right) \frac{\partial n_{E}^{*}}{\partial \widehat{R}}=-\frac{1-p}{\widehat{\gamma} p} \\
&-\frac{(1-F) \psi^{\prime \prime}}{\left(\psi^{\prime}\right)^{2}} \frac{\beta p \mu}{1-\beta p} \frac{\partial n_{I}^{*}}{\partial \widehat{R}}+\frac{1-\beta}{\widehat{\gamma} p \beta} \frac{\phi^{\prime}}{\phi^{2}} \frac{\partial n_{E}^{*}}{\partial \widehat{R}}=\frac{1-p}{\widehat{\gamma} p}
\end{aligned}
$$

Note that these two equations look identical with (11) and (12) except the RHS's. By the same logic applied in the proof of Proposition 4, we can show that $\partial n_{I}^{*} / \partial R<0$ and $\partial n_{E}^{*} / \partial R>0$.

For example, having free, fair and regular elections arguably reduces the cost of replacing the executive when necessary. So, democratization may expedite economic development directly and indirectly. First, a successful democratization would reduce the agency cost, and allow the participants of the social contract to have more public goods of higher quality. On top of that, if the country was in the poverty trap as illustrated in Section 5, the improvement in the public sector may help it get out of the trap. Once the economy successfully escapes the trap, the dynamic feedback mechanism would further reduce the agency costs and increase the overall productivity of the economy.

By the same logic, any change that makes the executive more difficult to replace would reduce the value of citizenship, thus reduce the quality of public sector. Political polarization might be such a change, because polarized citizens would care more about the polarized issue and less about the performance of the executive. See for instance Besley (2006, pp.124-128) for more on the effects of polarization. 


\subsection{Strong state apparatus}

It has been apparent from the beginning that the self-enforcement constraint increases the burden of self-government by worsening the agency problem on people's side. So, at least theoretically, the overall efficiency can be improved, if the government is allowed to punish those who misbehave more severely. Indeed, the evidence summarized in Keefer (2007) seems to suggest that at least among poor countries harsh governments are slightly more successful. However, it does not mean that in reality the most relentless governments would perform the best. In this subsection, I provide two arguments againt the idea that the strongest punishments are in general desirable for the society: (i) merciless punishment is suboptimal due to human errors in law enforcement; (ii) stronger state apparatus may allow greater room for political elites to pursue their own interests against those of the public.

As argued by Lagunoff (2001), if law enforcements are subject to human errors, which arguably is the case in reality, citizens will be hesitant to impose the harshest punishment on people who might be innocent. Thus, employing the severest punishment scheme in general would be suboptimal for at least two reasons. First, citizens ex-ante utility is not necessarily maximized with the severest punishment scheme, because they themselves may be punished by accident. Second, such "accident" may bring about backlashes which incur substantial social costs.

In reality, it is unlikely that some countries employ harsher punishment scheme because their law enforcers are making less mistakes than those in other countries. Historically, relentless governments have been imposed upon rather than constructed by the people. And, to keep their positions, some political leaders of such illegitimate governments might have no choice other than harshly suppressing their opponents and citizens. As byproducts, the laws in those countries might be more strictly followed, and their economies might perform better than those of more legitimate (i.e. self-enforcing) and democratic governments did. But it is still questionable whether such a "success" really improves citizens' welfare in general. More often than not, oppresive governments tend to serve the interests of political and economic elites over those of the public. If a government maximizes another objective than $V_{C}$, for instance the welfare of political elites, it is highly probable that the citizens are worse off, even when the agency problem on people's side is well-controlled.

Key point here is that the agency problem on people's side is not the only problem that a society has to deal with. In the formal models, it was assumed that having larger bureaucratic organizations and stronger state apparatus does not directly impact on the accountability of 
government. The assumption was adopted not because it is realistic but because it allows clearer presentation. In reality, strong state apparatus may expand room for rent-seeking behavior of political elites. If it is the case, two things are immediate. First, granting political elites the rights to punish citizens most harshly would not improve the welfare of the public. Second, the results associated with the resources spent in watching over citizens $n_{E}^{*}$ (Proposition 1, 4 and 6 ) would be strengthened, because by reducing such resources now the citizens can reduce the rents given to the political elites as well.

\subsection{Civic virtue and the role of history}

Numerous studies have argued that "civic virtue" or "social capital" plays a important role in workings of democracy. There would be many ways for civic virtue to enhance the quality of self-government, and here is one way. Suppose there are informal social networks, so a citizen is observed by at least one fellow citizen with probability $q$. If it is a social norm that any misbehavior is reported to the government, the probability of detection is now $q+\phi-q \phi$ which is greater than $\phi$. Accordingly, the resources spent in monitoring the private sector can be reduced. As the previous analysis has shown, this allows the society to spend more resources into disciplining the political elites and to construct a more democratic government.

Note that the social norm does not have to be the one assumed above. The social norm could be to ignore misbehavior of "friends", instead of to report it. In such case, the probability of detection remains as $\phi$ even when $q$ is positive. Thus, civic virtue should be sustained as an equilibrium of repeated interactions among the citizens, and can be broken or reinforced by historical events. ${ }^{16}$

\section{Conclusion}

This paper, by reformulating citizens-government relationship as a circular hierarchy, examines how economic, social and political fundamentals relate to the structure of government and the quality of public sector. The analysis shows that the agency problems within a social contract tend to exacerbate each other, so whenever the problem on one side is severe enough, the one on the other side is not negligible. This suggests that when we address government accountability issue, we may also have to pay attention to the incentives of citizens as agents. Static and dynamic feedback mechanisms with respect to the overall efficiency of public sector

\footnotetext{
${ }^{16}$ See Kandori (1995) for a game-theoretic model of social norm, and Putnam et al. (2001) for a study of social capital and civic virtue.
} 
are demonstrated. Through these mechanisms, small differences in economic and political fundamentals can be amplified into big differences in the structure of government and its policy making.

Ever since the idea of self-government was formalized in 18th and 19th centuries, Rousseau's and Madison's works have been constantly referred to in normative discussions. This contrasts sharply with that their legacies have not been very popular among scholars who are mainly interested in positive analysis. I do not intend to provide here a comprehensive geneology of the idea, but just to point out the results of this article do suggest a possible answer to the question why they have not been enthusiastically appreciated. The analysis shows that once a society is sufficiently developed in economic and political domains, the agency problem on people's side becomes negligible, in which case, researchers can safely ignore it and focus on the problem on the other side, namely the accountability of government. Therefore, it seems natural for scholars in already developed countries to pay more attention to government's side and less to people's. However, this strategy might not be valid when considering the political economy of developing countries which supposedly suffer significant agency problems on both sides. For those countries, the framework of the classical writers who lived in then poorly developed countries may fit better.

The models of this paper are very stylized, and missing many important features of the real world. In particular, for better understanding of people's self-control problem, two important issues which are abstracted from this paper should be further investigated. First, wealth inequality generates a different set of political problems which might interact with the agency problems. Second, the corruption of bureaucracy is also very notable feature in developing countries, and its interaction with other agency problems may also be an interesting topic of research.

\section{References}

[1] Acemoglu, Daron (2003), Why not a political Coase theorem? Social conflict, commitment and politics, Journal of Comparative Economics 31, 620-652

[2] Acemoglu, Daron (2005), Politics and Economics in weak and strong states, Journal of Monetary Economics 52, 1199-1226

[3] Acemoglu, Daron, Michael Golosov and Aleh Tsyvinski (2010), Dynamic Mirrless Taxation Under Political Economy Contraints, Review of Economic Studies 77(3), 841-881 
[4] Acemoglu, Daron, Davide Ticchi and Andrea Vindigni (2011), Emergence and Persistence of Inefficient States, Journal of European Economic Association 9(2), 177-208

[5] Besley, Timothy (2006), Principled Agents? The Political Economy of Good Government, Oxford University Press, Oxford

[6] Fearon, James D. (2011), Self-enforcing democracy, Quarterly Journal of Economics 126(4), 1661-1708

[7] Kandori, Michihiro (1992), Social Norms and Community Enforcement, Review of Economic Studies 59(1), 63-80

[8] Keefer, Philip (2007), The Poor Performance of Poor Democracies, in The Oxford Handbook of Comparative Politics, ed. Carles Boix and Susan C. Stokes, Oxford University Press, USA

[9] Laffont, Jean-Jacques (2000), Incentives and Political Economy, Oxford University Press, Oxford

[10] Lagunoff, Roger D. (2001), A Theory of Constitutional Standards and Civil Liberty, Review of Economic Studies 68, 109-132

[11] La Porta R., F. Lopez-de-Silanes, A. Shleifer and R. Vishny (1999), The quality of government, Journal of Law, Economics and Organization 15(1), 222-279

[12] Mailath, George J. and Larry Samuelson (2006), Repeated Games and Reputations: LongRun Relationships, Oxford University Press, Oxford

[13] Putnam, Robert D., Robert Leonardi and Raffaella Y. Nanetti (1993), Making Democracy Work. Civic Traditions in Modem Italy, Princeton University Press, Princeton

[14] Persson, Torsten, Gerard Roland and Guido Tabellini (1997), Separation of powers and political accountability, Quarterly Journal of Economics 112, 1163-1202

[15] Persson, Torsten, Gerard Roland and Guido Tabellini (2000), Comparative Politics and Public Finance, Journal of Political Economy 108, 1121-1161

[16] Przeworski, Adam (2005), Democracy as an Equilibrium, Public Choice 123, 253-273. 
[17] Przeworski, Adam, Michael E. Alvarez, Jose Antonio Cheibub, Fernando Limongi (2000). Democracy and Development, Political Institutions and Well-Being in the World, 19501990. Cambridge University Press, New York 